\title{
Apresentação
}

\section{Contribuições que estimulam a produção científica}

Ao usarmos a língua em forma de textos escritos ou orais, mostramos como eles são repletos do modo como olhamos e interpretamos o mundo, como é a língua que se fala, que se ouve, que se escreve. Vemos também como apresentamos nossas crenças e descrenças e quais são as nossas posições e opiniões sobre diferentes problemáticas. Com essa proposta, a Revista Domínios de Linguagem, nesse número, abriu espaço para ampliar o debate sobre pesquisas de diferentes temas e, consequentemente, estimular a produção científica.

A publicação contempla artigos destinados a pesquisadores, profissionais, professores e estudantes, de diferentes campos que apresentam interface com a Linguística. Este número reúne um conjunto de quatorze artigos originais um resumo e duas retrospectivas.

Apesar de distribuídas por ordem de entrada, as contribuições reunidas nesse número, de qualquer perspectiva de que as vemos, constituem reflexões sobre o fazer linguístico de diferentes enfoques, o que preserva a identidade deste volume cuja diversidade temática e teórica lhe é peculiar. A sequência apresentada dá uma amostra das atuais preferências temáticas na pesquisa sobre o ensino de línguas e sobre a Linguística.

O artigo "Verbos inergativos - itens lexicais de alternância causativo-incoativa" de Morgana Fabiola Cambrussi (UFFS) abre o número. O texto de Cambrussi apresenta um estudo sobre a alternância causativo-incoativa cujo predicador é um verbo inergativo e apresenta, ainda, uma proposta de análise de ocorrências dessa instância de alternância linguística no interior do português brasileiro. Para alcançar tal objetivo, a autora "relaciona ocorrências do fenômeno no português e no inglês e retoma a descrição desse tipo de alternância em trabalhos tomados como referência - especificamente, no de Levin (1993), estendendo-a aos dados do português”.

Uma segunda contribuição para esse número, intitulada "Práticas de leitura crítica no ensino superior: o gênero artigo Acadêmico”, de Marcela Langa Lacerda Bragança (UFFS - UFSC), apresenta os resultados de uma prática pedagógica desenvolvida em 
uma turma da universidade pública federal do estado do Paraná com o ensino de leitura do gênero artigo acadêmico. A proposição da autora considera os novos sujeitos que têm entrado no ensino superior depois do processo de expansão e interiorização das universidades públicas federais e parte do princípio de que a leitura crítica é relevante para consolidar o conhecimento. Segundo a autora, "o trabalho realizado constitui-se como um exemplo da contribuição para uma formação de qualidade desses novos universitários”.

Seguindo a mesma perspectiva de se trabalhar com gêneros, Sílvia Mônica Moura Lima (UFPI) apresenta o texto “A produção escrita do gênero $e$-mail nos livros didáticos de língua Inglesa”. A autora aborda o comportamento do gênero e-mail nas atividades propostas pelos livros didáticos e reflete sobre suas influências. Fundamentou-se em Bakhtin (1997), Miller (2012), Swales (2004), Bazerman (2009), Devitt (2004), Bunzen (2008), entre outros. Segundo a autora, “o ensino de gêneros na escola necessita se basear em suas ações sociais recorrentes”.

Na sequência, o artigo "Mapeamento construcional e fraseológico do verbo get: uma abordagem baseada na Linguística de Corpus e na Gramática de Construções Cognitiva”, Rodrigo Garcia Rosa (USP) e Stella E. O. Tagnin (USP) privilegiam unicamente os contextos em que o verbo get é seguido de complementos nominais com a finalidade de fazer um mapeamento. Embora os autores não considerem a discussão acerca do comportamento polissêmico de get finalizada, eles acreditam que os resultados obtidos na pesquisa contribuem para um melhor entendimento do comportamento construcional e fraseológico deste item lexical, tão recorrente na língua inglesa.

O próximo artigo apresentado faz uma análise semiótica do texto verbo-visual produzido para a publicidade do filme Ninfomaníaca de Lars Von Trier (2013). O título do texto de Juliane de Araujo Gonzaga (UNESP - FCLAr) é: “Do prazer ao mal-estar do sexo: análise semiótica da publicidade de Ninfomaníaca de Lars Von Trier”. A autora teve como aparato teórico pressupostos de Greimas e Floch concernentes à semiótica plástica, analisando a relação entre os modos de expressão visual e verbal para depreender as categorias de sentido fundamentais do texto apresentado em questão.

O linguista Ernesto Sérgio Bertoldo (UFU) apresenta "Pesquisa sobre o Ensino e a Aprendizagem de Línguas Estrangeiras: campos atravessados”. O interesse do autor, no referido artigo, diz respeito às mudanças ocorridas nas tendências de pesquisas, tendo em 
vista a possibilidade de mostrar e problematizar questões relativas aos estudos sobre o ensino e a aprendizagem de línguas estrangeiras. Vale ressaltar que, para efetivar o estudo, o autor levou em consideração o atravessamento desse campo de pesquisa por conceitos oriundos tanto da Análise de Discurso de orientação peucheutiana, quanto da Psicanálise Freudo-lacaniana. Faz um breve histórico dos principais tipos de pesquisa sobre o ensino e a aprendizagem de línguas estrangeiras que, tradicionalmente, constituíram as investigações nesse campo.

Thales Cardoso da Silva (UFSM) escreveu o artigo "Recursos Interpessoais em Artigos Audiovisuais de Pesquisa”. Esse estudo parte da hipótese “de que os artigos acadêmicos audiovisuais apresentam como recursos interpessoais três recursos à demanda de atividades: o modo oracional imperativo, modulação e metáforas interpessoais.” O autor conclui que mais pesquisas sobre as características deste gênero emergente, do qual ainda pouco se sabe, são necessárias e relevantes.

"Uma passagem marcante em A hora da estrela e em seus textos de chegada para o inglês” é o artigo de Roberta Rego Rodrigues (UFPel). Este artigo trata de uma análise estilístico-tradutória baseada em corpus de um diálogo em A hora da estrela (LISPECTOR, 1999) e o diálogo correspondente em seus textos de chegada para o inglês de Giovanni Pontiero (LISPECTOR, 1992) e de Benjamin Moser (LISPECTOR, 2011). Tem por objetivo conjeturar mediante à investigação da estrutura temática (HALLIDAY e MATTHIESSEN, 2014) traços estilísticos e prototípicos desse tipo de texto. Apesar de considerar seus achados inconclusivos, a autora espera ter fornecido dados que apontem para pesquisas de maior escopo.

Na sequência, o artigo "Eleições brasileiras de 2014, selfies e a criminalização de sua propagação via eventos digitais: um estudo crítico-discursivo”, de Jaime de Souza Júnior (UERJ), apresenta um estudo em que esse autor sugere a aplicação de um modelo de investigação voltado à análise da propagação de eventos digitais, os quais podem ser entendidos como eventos sociais, onde relações de poder, cada vez mais, vêm mostrandose representadas por diversos tipos de semioses, refletidas em práticas de produção e distribuição de linguagem e por mídia. Segundo o autor, o modelo desenvolvido no texto poderá ser aplicado para analisar a propagação e os modos ideológicos de operar presentes em outros tantos eventos digitais. 
O artigo “Aquisição e aprendizagem de línguas estrangeiras: princípios teóricos e conceitos-chave” de Kleber Eckert (IFRS - Bento Gonçalves) e Vitalina Maria Frosi (UCS) tem por objetivo subsidiar teoricamente professores e futuros professores de línguas estrangeiras acerca de alguns conceitos-chave em linguística aplicada ao ensino de línguas estrangeiras. Para tanto, “com base em princípios teóricos de vários estudiosos, faz-se uma síntese do que se convencionou chamar de aquisição e aprendizagem de línguas para depois chegar aos conceitos de língua materna e língua estrangeira, bem como às suas variantes e às implicações que essas variantes têm na perspectiva de uma língua estrangeira”.

André Luís Batista Martins (UFU) apresenta o texto “Essencialização da surdez em discursivizações do status linguístico da Libras e implicações educacionais” que aborda a questão da essencialização da surdez a partir de recortes acerca de discursivizações sobre o status linguístico da Língua Brasileira de Sinais e suas implicações no cenário inclusivista da educação nacional. O artigo problematiza a perspectiva de inclusão adotada nas escolas por não cnseguir manter uma coerência mínima entre seus pressupostos e as ações implementadas para conduzir o problema da educação da criança surda.

O texto "Do conceito de signo ao princípio do valor linguístico: ensaio sobre a dimensão do significado na teoria saussuriana da linguagem” de Aline Nardes dos Santos (Unisinos) e Rove Luiza de Oliveira Chishman (Unisinos) discute e inter-relaciona dois aspectos na obra de Saussure (1916) sobre a dimensão do significado a saber: a noção de signo lingüístico e o conceito de valor, que possui uma dimensão semântica. Esse estudo verifica as implicações trazidas por essa visão sistemática que consolidou a lingüística como ciência.

Carina Maria Niederauer,(UCS), em seu texto “Compreensão leitora: um discurso, várias vozes, um sentido", discute a questão da ausência de habilidade da compreensão leitora de alunos do Ensino Básico e Superior constatada por dados do PISA 2012. A autora propõe um estudo baseado na Teoria da Polifonia de Oswald Ducrot para promover o desenvolvimento das habilidades de compreensão leitora no que diz respeito à constituição do sentido dos discursos lidos.

O texto “O funcionamento discursivo de 'máscara’ no jornal Sineta - CPERS” de Luciane Botelho Martins (UCPel) busca examinar o processo discursivo em dois 
exemplares do jornal Sineta, periódicos do CPERS-Sindicato, a partir da análise de enunciados e imagens que compõem as capas onde constam os vocábulos “desmascara” e "máscara”. A autora aborda no artigo, dois momentos distintos: durante o governo Yeda Crusius (PSDB) e durante o governo Tarso Genro (PT). Partindo da hipótese de que os sindicatos são apoiados por partidos de esquerda e por isso assumiriam posições-sujeito diferentes ao produzirem discursos sobre os partidos dos governos citados (partidos ideologicamente divergentes), a autora utiliza a Análise do Discurso pecheuxtiana para verificar se isso ocorre. No decorrer da pesquisa, nota-se que esta hipótese não se confirma.

Ana Paula Scholl (UFRGS) apresenta uma resenha sobre o livro “Measuring L2 Proficiency” organizado por Leclercq, Edmonds e Hilton (2014) e publicado pela editora Multilingual Matters que tem como objetivo reunir textos de pesquisas sobre diferentes aspectos da "Aquisição de Segunda Língua” com o intuito de atenuar a lacuna entre a pesquisa nessa área e o ensino de línguas. As contribuições dos pesquisadores presentes no livro focalizam, em especial, os construtos sobre confiabilidade e viabilidade da avaliação da proficiência em uma segunda língua.

A retrospectiva de Vicentônio Régis do Nascimento Silva (UEL) e Daniele Trevelin Donato (UNESP - Assis) intitulada “Comunicação e Discurso” traz a obra organizada por Roseli Figaro “Comunicação e Análise do Discurso” publicado pela editora Contexto em 2013 que contempla o resultado de artigos expostos em seminários na Escola de Comunicação e Artesda USP - I Ciclo de Estudos: Comunicação, Análise de Discurso e Atividade Linguageira que possui como objetivo a apresentação de linhas teóricas na compreensão da Análise do Discurso aplicando-as aos textos jornalísticos, publicitários literários, políticos e iconográficos.

Fechando a revista, Thays Caroline Barroca Ribeiro Morettini (UEL) apresenta a retrospectiva “Texto ou Discurso?” sobre a obra com o mesmo título de Brait e Souza-eSilva (2012), publicada pela Contexto, que discute a complexidade das reflexões exigidas para se compreender os termos texto e discurso, ressaltando pontos de vista teóricos e metodológicos diferenciados que revelam distintas concepções e formas de abordagens da linguagem. As reflexões apresentadas nessa obra permitem que o leitor - pesquisador compreenda de forma pontual a distinção entre os dois termos, bem como sua interdependência. 
Por fim, vale ressaltar que esse é, em suma, o conteúdo, em dimensão panorâmica, desse volume. São textos que, sem dúvida, trazem a provocação para um debate científico acerca de diferentes tópicos relacionados à Linguística ou que apresentem interface com essa ciência com o objetivo, entre outros, de subsidiar outras pesquisas.

Boa leitura! 